\title{
Evaluation of cobalt in the cyanocobalamin solution using the method of inverse voltammetry with a rotating disk electrode
}

\author{
(C) Anna I. Fokina, ${ }^{1}{ }^{+}$Vasily N. Kulakov, ${ }^{1}$ \\ Tamara Ya. Ashikhmina, ${ }^{2}$ and Elena A. Klekovkina ${ }^{1}$ \\ ${ }^{1}$ Department of Fundamental Chemistry and Methods of Teaching Chemistry. Institute of Chemistry \\ and Ecology. Vyatka State University. Moskovskaya St., 36. Kirov, 610000. Kirov Region. Russia. \\ Phone: +7 (332) 35-64-65. E-mail: annushka-fokina@mail.ru. \\ ${ }^{2}$ Biomonitoring Laboratory. Institute of Biology of the Komi Scientific Center. Ural branch of the Russian \\ Academy of Sciences. Kommunisticheskaya St., 28. Syktyvkar, 167982. Komi Republic. Russia. \\ Phone: +7 (332) 37-02-77. E-mail: usr08619@vytsu.ru
}

Keywords: cobalt, inverse voltammetry, cyanocobalamin.

*Supervising author; ${ }^{+}$Corresponding author

\begin{abstract}
Inverse voltammetry is a very perspective method due to its relative simplicity, cost effectiveness, and sensibility. Universality of this method allows scientists to find new objectives, both organic and inorganic nature, for the use of the method. Some results of the improvement and adaptation of the standardized methodology for cobalt identification with a rotating disk electrode implemented on the analyzer «Ecotest-VA» with the «EM-04» module for the identification of the mass concentration of this metal in the medication «Cyanocobalamin» is presented in this article.

The arrival of an analytical signal in the form of peaks on a voltamperogram during the quantitative determination of cobalt results from the adsorptive concentration of cobalt-dimethylglyoxime complexes on the surface of the working cathode. Cathode current registered when $\mathrm{E}_{\max }=(-1.1)-(-1.2) V$ is compliant with catalytic current of electrochemical reduction of hydrogen from adsorbed cobalt dimethylglyoxime and is an analytical signal of a measured ion, in the present case - of cobalt. Peak height (area) is proportional to the metal-ion concentration in the solution.

It is necessary to carry out the sample preparation of the medication and a solution for additive components for the implementation of the analysis method when determining the mass concentration of the metal in the cyanocobalamin solution. The cyanocobalamin solution with the addition of hydrogen peroxide is maintained in a photolysis camera for the transportation of cobalt into the solution as a $\mathrm{Co}^{3+}$. The solution for additive components is boiled with hydrogen peroxide to convert $\mathrm{Co}^{2+}$ into $\mathrm{Co}^{3+}$.

Using the developed method, the evaluation of cobalt in the medication «Cyanocobalamin» $(0.5$ $\mathrm{mg} / \mathrm{cm}^{3}$ ) was conducted. Validation of the results obtained was carried out with the use of the technique «entered-identified».
\end{abstract}

\section{References}

[1] OFS.1.2.3.0017.15 Methods for the quantitative determination of vitamins.

[2] A.V. Kolesnikov. Investigation of the effect of surfactant in the inversion-voltammetric method analysis of metals. Butlerov Communications. 2016. Vol.47. No.7. P.93-96. DOI: 10.37952/ROI-jbc-01/16-47-7-93

[3] E.I. Lyalina, A.I. Fokina, T.Ya. Ashikhmina, and M.A. Mingazov. The determination of the restored glutathione by method of an inverse voltamperometry on the analyzer with the rotating disk carbositall electrode. Butlerov Communications. 2016. Vol.48. No.10. P.119-127. DOI: 10.37952/ROI-jbc-01/16-48$10-119$

[4] A.V. Sidelnikov, R.R. Nigmatullin, V.N. Maystrenko, H.C. Budnikov, E.I. Maksyutova, and A.A. Tikhonova. PCA-analysis of tryptophan enantiomers voltammetric time rows under continuous sensor functioning conditions. Butlerov Communications. 2017. Vol.51. No.9. P.94-102. DOI: 10.37952/ROI-jbc01/17-51-9-94

[5] R.A. Zilberg, Yu.A. Yarkaeva, D.I. Dubrovsky, A.I. Khabletdinova, and V.N. Maistrenko. Voltammetric "electronic tongue" for recognition of methionine-containing pharmaceuticals. Butlerov Communications. 2018. Vol.56. No.11. P.32-37. DOI: $10.37952 / R O I-j b c-01 / 18-56-11-32$ 
[6] O.L. Mezentseva, G.B. Slepchenko, V.D. Filimonov, E.V. Mikheeva, G.A. Arbit. Determination of halon and benzonal in tablet formulations of drugs by stripping voltammetry. Analytics and control. 2018. Vol.22. No.2. P.206-213. (russian)

[7] Milan Sýs, Amir Shaaban Farag, Ivan Švancara. Extractive stripping voltammetry at carbon paste electrodes for determination of biologically active organic compounds. Monatshefte für Chemie Chemical Monthly. 2019. Vol.150. Iss.3. P.373-386.

[8] Zahra Mofidi, Parviz Norouzi, Masumeh Sajadian. Simultaneous extraction and determination of trace amounts of diclofenac from whole blood using supported liquid membrane microextraction and fast Fourier transform voltammetry. J. of Separation science. 2018. P.1644-1650. doi.org/10.1002/jssc.201701119

[9] Collection of methods for measuring the concentration of copper, cadmium, zinc, bismuth, manganese, and nickel ions using voltammetry on the Ecotest-VA voltammetric analyzer. Moscow: LLC EconixExpert. 2004. 61p. (russian) 